\title{
ESCRITA DE MEMÓRIAS: UM EXERCÍCIO DE REFLEXÃO SOBRE A VIDA
}

\author{
MEMORIES WRITING: A REFECTION EXERCISE ABOUT LIFE
}

DOI: http://dx.doi.org/10.23926/RPD.2526-2149.2018.v3.n2.p445-452.id247

\section{Camila Santos \\ Andrade \\ Bolsista do Programa \\ Institucional de Bolsa de \\ Iniciação Científica (PIBIC- \\ IFAL). \\ camilasantos.asc@gmail.co}

$\underline{\mathrm{m}}$

\section{João Gonçalves \\ Torres-Filho}

Bolsista do Programa

Institucional de Bolsa de

Iniciação Científica da

Fundação de Amparo à

Pesquisa do Estado de

Alagoas (FAPEAL).

igoncalvestorresf@gmail.co m

\section{Flávia Karolina Lima- Duarte}

Mestra em Linguagem e

Ensino (UFCG).

Professora EBTT (IFAL).

Doutoranda em Letras e

Linguística (UFAL).

Bolsista de Produtividade do

Programa de Apoio à

Produtividade em Pesquisa

(PAPE/IFAL).

flaviakarolinalima@gmail.co

$\mathrm{m}$
Resumo: Escrever memórias é uma das formas de manter algumas lembranças vivas em nossas vidas. Em ambientes de encarceramento essa busca pelas memórias é constante, pois esse exercício possibilita a fuga da realidade. Nessa perspectiva, esta pesquisa tem por objetivo ampliar o interesse pela escrita de gêneros autobiográficos em uma Unidade de Internação Feminina e, consequentemente, pela leitura literária. O referencial teórico está representado por estudiosos do gênero autobiográfico-memórias (EIBER et al., 1999; RADVANSKY et al., 2005). A metodologia incluiu reflexão acerca do texto imagético presente na obra trabalhada, Becos da Memória, de Conceição Evaristo. Os dados para análise são constituídos por memórias produzidas pelas adolescentes internas. A pesquisa apresentou como resultado o estímulo às práticas de leitura e escrita e reflexão acerca de suas vidas.

Palavras-chave: Ensino de Língua Portuguesa. Escrita de memórias. Unidade de Internação Feminina.

Abstract: Writing memories is a way of keeping some of our remembrances alive. In incarceration environments, this search for memories is constant, thus this exercise allows escaping from reality. In this perspective, this research aims to enhance the interest for writing (auto)biographical genres in one Female Hospitalization Unit $\mathrm{e}$, therefore, for literary literature. The theoretical framework is represented by researchers of the autobiographical-memories genre (EIBER et al., 1999; RADVANSKY et al., 2005). The methodology includes a reflection about the imagetic text present in the book, Becos da Memória, by Conceição Evaristo. The data for analysis is constituted by produced memories from the hospitalized teenagers. The research showed as a result the push to the reading and writing practice and reflection about their lifes.

Keywords: Teaching of the Portuguese Language. Memorialist writing. Female Hospitalization Unit. 


\section{INTRODUÇÃO}

Esse artigo resultou de um projeto de Pesquisa de Iniciação Científica (PIBIC), financiado pela Pró-Reitoria de Pesquisa do Instituto Federal de Alagoas. Esta pesquisa objetivou incentivar a leitura e a produção escrita de gêneros autobiográficos em ambiente de privação de liberdade. Normalmente, nessas instituições, as encarceradas ficam muito ociosas, portanto, possuem mais tempo para refletir sobre suas vidas e, em geral, o fazem oralmente, ou seja, compartilham suas histórias com as colegas.

Refletindo sobre esse contexto, iniciou-se, em 2016, um projeto de pesquisa em uma Unidade de Internação Feminina de Maceió que atende jovens em conflito com a lei. Naquela etapa, trabalhou-se com o gênero confessional diário, isto é, as adolescentes tiveram a oportunidade de ler e refletir sobre o Diário de Anne Frank e de escrever seus próprios diários (LIMA-DUARTE et al., 2017). A partir dos resultados obtidos, decidiu-se dar continuidade à pesquisa por mais um ano, mas, agora, com foco na escrita de outro gênero autobiográfico: memórias.

Iniciou-se o trabalho com a importante tarefa da escolha do livro para as rodas de leitura literária. Para tanto, contamos com a colaboração de uma colega de departamento ${ }^{1}$. A partir dessa indicação selecionamos a obra Becos da Memória, de Conceição Evaristo (2017), que retrata diversos problemas sociais, porém o foco neste livro é a questão da moradia, ou seja, a autora recorre as suas lembranças de quando vivia em uma favela e foi despejada. Ela retrata também as histórias dos moradores e mostra como eram suas vidas antes e depois da notícia da desocupação.

Com base no exposto, considerou-se que as estudantes da Unidade de Internação Feminina teriam interesse na obra, visto que elas possuem uma enorme admiração pelas favelas, o que possibilitaria a aproximação delas com a leitura literária. Defendemos, portanto, que essa identificação com Beco das Memórias poderia servir de inspiração para que elas pudessem escrever suas histórias pessoais.

\section{REFERENCIAL TEÓRICO}

Fisiologicamente falando, a memória é a capacidade de conservar ideias, fatos e imagens que poderão ser acessadas futuramente. Dentre a miríade de eventos específicos que acontecem ao longo de uma vida, nem todos ocasionam registros duradouros a ponto de serem

\footnotetext{
${ }^{1}$ Agradecemos a Professora Doutora Cleusa Salvina Barbosa, líder do Grupo de Pesquisa Múltiplos Olhares sobre a Linguagem (MOLI), por sugerir a obra de Evaristo Conceição. 
lembrados em longo prazo (WESTBURY; DENNETT, 2000), ou seja, a memória é uma seleção, algumas lembranças serão conservadas, outras serão imediatamente ou progressivamente deixadas de lado.

Na literatura confessional a memória autobiográfica está intimamente ligada com a história, contudo, consideramos importante trazer a reflexão do grande escritor espanhol Miguel de Cervantes (1605, p. 325).

Uma coisa é escrever como poeta, e outra coisa como historiador. O poeta pode contar ou cantar as coisas, não como foram mas como deviam ser; e o historiador há-de escrevê-las, não como deviam ser e sim como foram, sem acrescentar ou tirar nada à verdade.

Assim sendo, a escrita de memória literária não tem compromisso com a verdade, mesmo que esteja intimamente relacionada com a história. Diferentemente das memórias da literatura confessional, em que memória e história se relacionam, em ambiente de privação de liberdade as internas escrevem as memórias de suas vidas, isto é, buscam relembrar fatos importantes por elas vividas.

Destaca-se que este tipo de escrita contribui para que elas possam se (auto)definir, se (re)conhecer em sua própria experiência e se expressar a partir de suas trajetórias singulares (SINGER; SALOVEY, 1993; BLAGOV; SINGER, 2004). Nesse sentido, a escrita de memória permite ao sujeito registrar e evocar informações num determinado contexto espacial e temporal, por vezes inespecíficos, permitindo que no futuro possam se recordar de fatos de sua história pessoal, familiar ou social (EIBER et al., 1999).

Em relação à escrita de memórias, a progressão desse gênero ocorre, em geral, pela tipologia narrativa, visto que a pessoa organiza as lembranças vividas similarmente à organização de uma história. A linguagem possibilita que a memória autobiográfica seja analisada de forma objetiva - através das sequências de ações e eventos, ou subjetiva - por meio da relação entre o recordar e o inferir (RADVANSKY et al., 2005).

Diante do exposto, pretendeu-se que as adolescentes participantes do projeto obtivessem o interesse pela leitura de memórias e, a partir disso, escrevessem suas memórias para que pudessem refletir sobre suas ações.

\section{Metodologia}

A Unidade de Internação Feminina (UIF) de Maceió é uma das instituições responsáveis pela aplicação da medida socioeducativa em Alagoas. As colaboradoras da pesquisa foram adolescentes, de 13 a 18 anos, em conflito com a lei, que cumprem medidas socioeducativas na 
Unidade de Internação Feminina (UIF) de Maceió. A maioria está nesse ambiente por envolvimento com o tráfico e uso de drogas. Destaca-se que, em geral, a aproximação com a criminalidade se dá por influência dos seus parceiros/namorados.

Demos início a essa nova etapa da pesquisa após recebermos as autorizações do Juizado da Infância da Capital, que responde legalmente pelas adolescentes, dos gestores da UIF e das direções geral e de pesquisa do IFAL.

No primeiro contato com as adolescentes da UIF, em novembro de 2017, realizou-se a exposição do projeto, em que foi relatada a importância da participação delas e a necessidade de lerem o livro Becos da memória, de Conceição Evaristo, e, a partir disso, escreverem suas memórias. Nesse primeiro encontro pedimos para que elas escolhessem seus nomes fictícios, visto a necessidade de preservar a identidade das adolescentes.

O procedimento metodológico para geração de dados se deu a partir de rodas de leituras e escrita. Tendo em vista que o livro estudado era subdivido em contos que apresentavam diversas temáticas, em cada encontro lia-se em voz alta uma narrativa, em seguida refletia-se acerca das questões socias abordadas e, por fim, produzia-se memórias temáticas, conforme detalhado (Quadro 1).

\begin{tabular}{|c|c|c|}
\hline Data & Etapa & Descricão das atividades \\
\hline $05 / 12 / 2017$ & Apresentação do livro & Introdução do livro e debate sobre as fotos do livro. \\
\hline $12 / 12 / 2017$ & $\begin{array}{l}\text { Leitura e debate sobre o } \\
\text { livro }\end{array}$ & Início da leitura e produção de memórias \\
\hline 09/01/2018 & $\begin{array}{l}\text { Leitura e produção de } \\
\text { memórias }\end{array}$ & $\begin{array}{l}\text { Leitura do livro e produção de memórias sobre o natal e ano } \\
\text { novo }\end{array}$ \\
\hline $18 / 01 / 2018$ & $\begin{array}{l}\text { Leitura e debate sobre o } \\
\text { livro }\end{array}$ & Trechos selecionados e produção de texto sobre esses \\
\hline 25/01/2018 & Leitura do livro & $\begin{array}{l}\text { Continuação da leitura do livro, produção de memórias tristes } \\
\text { e sobre o primeiro dia na unidade }\end{array}$ \\
\hline 08/02/2018 & $\begin{array}{l}\text { Leitura do livro e produção } \\
\text { de memórias }\end{array}$ & $\begin{array}{l}\text { Leitura final do livro, debate sobre as impressões do livro, } \\
\text { personagens e contexto. Produção de resenha sobre o livro e } \\
\text { memória sobre família }\end{array}$ \\
\hline
\end{tabular}

No quadro 1, demonstra-se que a coleta de dados foi composta por seis encontros e em todos eles foram realizados a escrita de memórias temáticas. Para este artigo o corpus a ser analisado são os do primeiro encontro, realizado no dia 05 de dezembro de 2017.

\section{Resultados}

Nossa proposta para a primeira oficina foi a de apresentar as imagens do livro para as adolescentes, visto que a capa e a contracapa da obra são compostas pelas fotografias dos 
moradores da favela que fizeram parte da vida e das memórias de Conceição Evaristo. Decidimos iniciar com essa abordagem porque as fotos possuem um papel importante em nossas vidas e contribuem para a preservação das nossas memórias, pois, quando nos fotografamos, congelamos o tempo para preservar as lembranças de um momento especial.

A partir da leitura das imagens que compõem o livro pedimos às participantes que escolhessem uma foto e, com base nessa escolha, deveriam escrever uma memória a respeito da sensação que a foto lhes provocou.

Marluci escreveu sua memória baseado na representação da foto de uma senhora idosa (Figura 1).

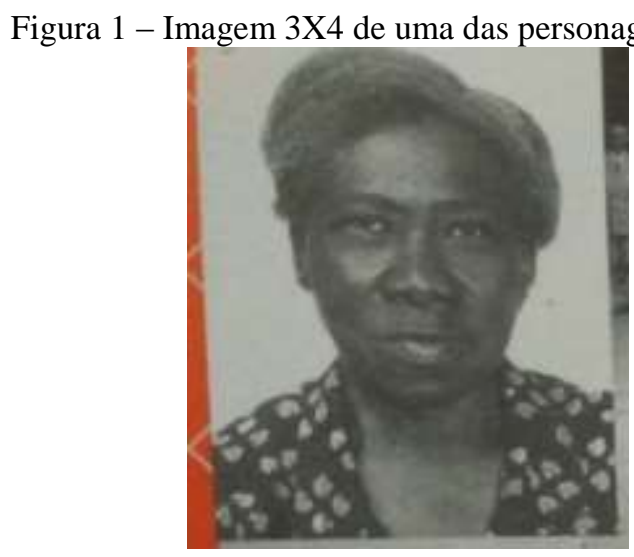

Fonte: Evaristo (2017).

Essa imagem avocou-lhe a lembrança de sua mãe e a tristeza por não poder estar ao lado dela nesse momento em que a velhice se aproxima.

\begin{abstract}
A fotografia que eu vi, foi de uma senhora. Lembrei da minha mãe que estar ficando velhinha, e não estou podendo cuidar dela no momento mais prometi pra mim mesma que quando sair daqui vou cuidar do meu pai e dela e recuperar esse tempo perdido, vou trabalhar pra ajudar os dois não quero ver mais ela se esforçando, decide totalmente mudar de vida depois de uma conversa com meu pai, abrir totalmente meu coração. (Transcrição da memória de Marluci, 05/12/2017, SIC)².
\end{abstract}

A Figura 1, da senhora negra e de cabelos brancos, fez com que a socioeducanda pensasse em seus pais e na idade deles, e, consequentemente, lembrou-se que durante a velhice as pessoas precisam de mais cuidado, portanto, como filha, sente-se no dever de cuidar de seus pais e a necessidade de estar perto deles. Recordou-se também da promessa feita ao seu pai, que ao sair do cárcere será uma filha mais responsável e irá recuperar o "tempo perdido". Essa escrita memorialística possibilitou-lhe a reflexão da importância do vínculo familiar, o que lhe faz planejar ser uma filha melhor no futuro.

\footnotetext{
${ }^{2} \mathrm{Na}$ pesquisa foram preservados os dados originais do relato, sem ajustes para a língua padrão.
} 
Depreende-se da escrita de Marluci que o exercício de escrita memorialística lhe possibilitou a reflexão acerca da importância dos pais e de se avaliar como filha, posto que ao dizer que será mais responsável percebe que cometeu erros.

Branquinha também refletiu a respeito da fig. 1, ela disse que: "Lembrou a mãe do meu parceiro que mataram... eu gosto muito dele nunca sairá da minha mente. Te amo, Bicudo.” (Transcrição da memória de Branquinha, 05/12/2017). Diferentemente de Marluci, essa imagem fez com que Branquinha pensasse em seu amado, por associação da foto com a mãe de Bicudo. Nessa memória podemos inferir que seu parceiro também vivia na criminalidade, quando ela diz que ele foi morto. Essas histórias de relações amorosas prejudiciais são muito presentes na Unidade de Internação Feminina, porque a maioria das adolescentes entra para a criminalidade por influência de seus namorados/parceiros. Essa lembrança de Branquinha aponta também para a compreensão de que ela não percebe o quão negativo foi esse relacionamento, visto que ela afirma que ainda o ama.

Por fim, destacamos a memória afetiva de Angelina a partir da foto de uma família (Figura 2).

Figura 2 - Foto Familiar

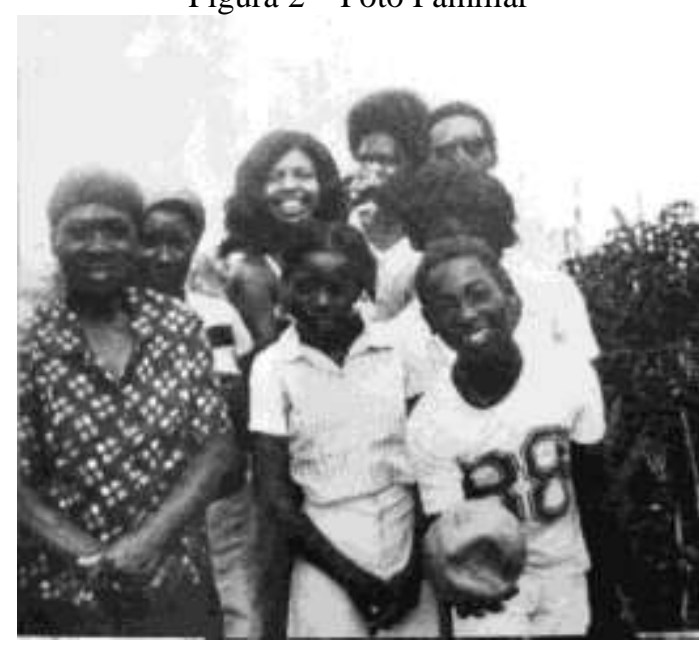

Fonte: Evaristo (2017).

A Figura 2, de uma família alegre, provocou na adolescente a lembrança de alguns familiares: "Lembrei da minha avó com o meu avô e minhas tias em frente a casa dela com minha mãe e é isso" (Transcrição da memória de Angelina, 05/12/2017, SIC). Apesar de ser uma memória curta, não é menos importante que as outras, visto que esse ambiente em que elas estão inseridas possibilita-lhes refletir bastante sobre suas famílias. Além disso, essa foi a primeira atividade de exercício de escrita de memórias. 
Um dado importante nessa lembrança de Angelina trata-se da ausência paterna, posto que, ao não citá-lo, podemos compreender que ele não se fez presente em sua vida. Essa informação pode ser constatada em outros momentos das rodas de leitura e escrita (verficar Quadro 1), pois ao escrever acerca de seus familiares, Angelina tampouco menciona o pai. Citamos como exemplo um trecho da memória de festas de fim de ano: "Foi bom, pois estava com minha família: mãe, sobrinhos, tios. E meu ex-marido, fizemos uma ceia, amanhecemos o dia na casa da minha mãe. (Transcrição de um trecho da memória de Angelina, 09/01/2018). Veja que Angelina não fala do seu pai, o que reforça os problemas familiares e a desestrutura familiar, muito recorrentes nesse contexto de encarceramento.

\section{CONSIDERAÇÕEs FinAis}

Começamos mostrando as fotografias para introduzir a história do livro, com o intuito de que a partir dessas imagens as socioeducandas se aproximassem de suas memórias. Como foi dito anteriormente, algumas memórias podem ser despertadas através de fotos, por isso optamos por esse método e obtivemos êxito nessa tarefa. Apesar de as memórias escritas por elas não seguirem a estrutura da tipologia narrativa, esses pequenos recortes de suas lembranças foram importantes para que pudessem exercitar e, a partir disso, escrever em seus cadernos de memórias.

Assim sendo, esse trabalho serviu de estímulo para que as meninas se sentissem motivadas a escrever, pois perceberam que esse tipo de escrita lhes possibilita o exercício de refletir sobre suas ações e escolhas. Além disso, contribui também para o processo de compreensão da língua portuguesa, pois sempre perguntavam quando tinham dúvida em relação aos usos da linguagem.

Destaca-se também que esta pesquisa despertou nas socioeducandas o gosto pela leitura. Isto é, ao concluírem a leitura dessa obra procuraram outros livros para ler, conforme foi dito por Luzia em uma memória escrita após a finalização do livro: “Hoje me afundo em qualquer livro, consigo entrar nele e viver ele, até parece bobagem, mas é isso que eu sinto, muito obrigada por tudo Becos da memória" (Transcrição de um trecho da memória de Luzia, 08/02/2018).

Por fim, consideramos que essa pesquisa contribuiu bastante para que elas pudessem refletir sobre suas vidas, como vimos na transcrição da memória de Marluci, que se propõe a ser uma filha mais presente e mais responsável. Isso reforça a necessidade de se levar mais projetos como este para esses ambientes de privação de liberdade. 


\section{REFERÊNCIAS}

BLAGOV, P. S.; SINGER, J. A. (2004). Four dimensions of selfdefining memories (specificity, meaning, content, and affect) and their relationships to self-restraint, distress, and repressive defensiveness. Journal of personality, 72, 481-512.

CERVANTES, M. Dom Quixote, 1605. Disponível em:

$<$ http://docente.ifrn.edu.br/paulomartins/livros-classicos-de-literatura/dom-quixote-de-lamancha-de-miguel-de-cervantes.-pdf/view>. Acessado em: 18 jun. 2018.

EIBER, R.; PUEL, M. SCHMITT, L. Heroin abuse, autobiographical memory and depression. Encephale. 1999; 25 (6): 549-57. French.

LIMA-DUARTE, Flávia Karolina; TORRES-FILHO, João Gonçalves; GAIA, Rossana Viana. Eu e meus eus: leitura e escrita de diário em uma Unidade de Internação Feminina. Letras raras. 2017. ISSN 2317-2347. Disponível em:

<http://revistas.ufcg.edu.br/ch/index.php/RLR/article/view/859/541>. Acessado em: 28 de jul. 2018.

RADVANSKY, G.; COPELAND, D.; ZWAAN, R. A novel study: investigating the structure of narrative and autobiographical memories. Memory. 2005;13(8):796-814.

SINGER, J. A.; SALOVEY, P. (1993). The remembered self: Emotion and memory in personality. New York: Free Press.

WESTBURY, C. \& DENNETT, D. C. (2000). Mining the past to construct the future: Memory and belief as forms of knowledge. Em D. L. Schacter \& E. Scarry (Eds.), Memory, brain, and belief (p.11-32). Cambridge, MA: Harvard University Press.

Recebido em: 17 de agosto de 2018.

Aprovado em: 4 de dezembro de 2018. 